\title{
Corrosion of brass in natural and artificial seawater under anaerobic conditions
}

\author{
M. C. Bastos · M. H. Mendonça • M. M. M. Neto • M. M. G. S. Rocha • \\ L. Proença $\cdot$ I. T. E. Fonseca
}

Received: 12 October 2007/Revised: 16 December 2007/ Accepted: 7 January 2008/Published online: 25 January 2008

(C) Springer Science+Business Media B.V. 2008

\begin{abstract}
The corrosion of brass in deoxygenated nonbuffered and buffered artificial and natural seawater was studied. The weight gains and the average corrosion rates of brass samples, immersed in both media during periods of 1 week, 1 and 3 months, were determined.

The morphology of the corroded surfaces, with and without the corrosion products, was analyzed by visual observation and scanning electron microscopy (SEM). Energy dispersive spectroscopy (EDS) was used for the identification of the corrosion products and X-ray diffraction (XRD) for the identification of the crystalline corrosion products.

In general it was concluded that deoxygenating and buffering, at $\mathrm{pH} 9$, both contribute to enhance the corrosion of brass in seawater.
\end{abstract}

Keywords Anaerobic conditions - Artificial seawater (ASW) · Brass · Natural seawater (NSW) - SEM/EDS . Biofilms

M. C. Bastos · M. H. Mendonça - M. M. G. S. Rocha

L. Proença $\cdot$ I. T. E. Fonseca $(\bowtie)$

CCMM, Departamento de Química e Bioquímica, Faculdade de Ciências, Universidade de Lisboa, Campo Grande, Ed. C8, 1749-

016 Lisboa, Portugal

e-mail: itfonseca@fc.ul.pt

M. M. M. Neto

Departamento de Química Agrícola e Ambiental, Instituto

Superior de Agronomia, Tapada da Ajuda, TULisbon, 1349-017

Lisboa, Portugal

L. Proença

Instituto Superior de Ciências da Saúde Egas Moniz, Quinta da Granja - Monte de Caparica, 2829-511 Caparica, Portugal

\section{Introduction}

Copper and its alloys are widely used in marine environments due to their corrosion resistance, mechanical workability, excellent electrical and thermal conductivities and good resistance to biofouling. Brass is used extensively in marine applications and in heat exchanger tubes, for example in desalination and power generation plants, respectively.

It is well known that the aggressivity of seawater is mainly due to its chloride content. However, other factors such as the presence of microorganisms can play an important role, since biofilms are a radically different environment in terms of $\mathrm{pH}$, dissolved oxygen and other species i.e. extracellular polymeric substances (EPS). Also the dissolved organic matter and colloidal substances present in the NSW may influence the corrosion behaviour of brass when compared with the corresponding immersions in ASW. The alloys can deteriorate due to the formation of biofilms, whose polymeric structure allows local gradients of $\mathrm{pH}$ and $\mathrm{O}_{2}$ to exist [1]. Although the microbiologically influenced corrosion of carbon and stainless steel has been widely studied, there has been little investigation on copper and copper alloys [2-10]. Mansfeld and Little [3] concluded that copper alloys exposed to natural seawater (NSW) were colonized by bacteria in 3 weeks and that in all cases the corrosion rates in NSW were higher than those in artificial seawater (ASW).

Kharafi et al. [7] observed selective dissolution of brass at various potentials and chloride concentrations, and concluded that chloride promotes the dissolution of copper and also of zinc. In a previous study on the corrosion of brass in non-deoxygenated non-buffered seawater solutions $[9,10]$ we have observed higher weight gains and higher 
corrosion rates on the brass samples immersed in NSW. Naguib and Mansfeld [11] studied the corrosion behaviour

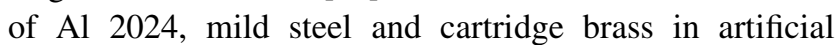
seawater (ASW) containing a growth medium contaminated by bacteria. Under sterilised conditions they concluded that the corrosion behaviour was similar to that in ASW without bacteria.

Huang et al. [5] emphasized the importance of performing studies in NSW, under anaerobic conditions. After 7 days of immersion in the SRB-containing seawater, they noticed that the SRB attached on the alloy surface formed a biofilm and lead to intergranular corrosion. Consequently, a significant decrease in the polarization resistance was observed. Under anaerobic conditions, $\mathrm{O}_{2}$ is not present and the cathodic reactant may be $\mathrm{H}_{2} \mathrm{O}$ and/or organic compounds, or products from the microbial activity, particularly in NSW, or in contaminated ASW. Anaerobic bacteria may grow, and the products from their activity (EPS) may lead to significant compositional changes which modify the aggressiveness.

In the above-mentioned studies $[9,10]$ dealing with the corrosion of brass in non-deoxygenated non-buffered seawater solutions, we measured changes in the $\mathrm{pH}$ values, from 8 to 5.5, during the exposure, as well as a decrease in the oxygen content, starting at $13 \mathrm{ppm}$ and ending at $0.3 \mathrm{ppm}$, on the 6 months exposure. In order to have a deeper insight and get more information on the corrosion of brass under anaerobic conditions, a systematic study carried out in natural seawater (salts, microorganisms, organic matter, EPS from microbial activity, etc.) and non-sterilised artificial seawater (only salts and eventually microbial contamination) is presented here. We also performed experiments in buffered solutions to reduce the number of factors influencing the corrosion process.

To support the hypothesis that the enhancement of corrosion in NSW is related with the SRB activity, it would be interesting to perform experiments in sterilised NSW or in ASW contaminated only with the EPS extracted from a culture of SRB, or inoculated with a culture of SRB. We also recognize that studies with brass samples exposed directly in the ocean, where the seawater samples were collected, can bring additional information. However, such studies require a special experimental setup.

\section{Experimental details}

Coupons of brass $(63.8 \% \mathrm{Cu} ; 36.1 \% \mathrm{Zn} ; 0.018 \% \mathrm{Fe}$; $0.009 \% \mathrm{Ni} ; 0.008 \% \mathrm{~Pb} ; 0.007 \% \mathrm{Sn}$ and $0.001 \% \mathrm{Al}$ ), with dimensions of $1 \mathrm{~cm} \times 2.5 \mathrm{~cm} \times 0.1 \mathrm{~cm}$, were used for weight loss studies in natural and artificial seawater, in triplicate for each medium and exposure time. All the coupons were polished with emery paper and alumina powder down to $0.05 \mu \mathrm{m}$, rinsed several times with distilled water, degreased with acetone, washed again with distilled water and dried. All coupons were weighed prior to and after exposure.

McCartney bottles were used. The coupons were transferred to the exposure bottles, containing deoxygenated buffered aqueous solutions of natural and artificial seawater. During the exposure periods deoxygenation was achieved by bubbling $\mathrm{N}_{2}$ above the solutions.

ASW was prepared by dissolving $40 \mathrm{~g}$ of Sea Salts from a Sigma Cell Culture in $1 \mathrm{~L}$ of deionised Millipore ${ }^{\circledR}$ MilliQ water. NSW was collected in a brown flask, at Ericeira beach on the western coast of Portugal, in March 2006; the sample was transported and kept in the laboratory at $4{ }^{\circ} \mathrm{C}$. Chemical analysis of the NSW samples was carried out according to standard methods [12]. The chemical composition and physical properties of both samples of seawater are given in Tables 1 and 2, respectively. Buffering $(\mathrm{pH} 9)$ was achieved using borax buffer $(0.025 \mathrm{M}$ $\mathrm{Na}_{2} \mathrm{~B}_{4} \mathrm{O}_{7}+0.05 \mathrm{M} \mathrm{H}_{3} \mathrm{BO}_{3}$ ).

It should be pointed out that ASW (Sigma Aldrich) contains only inorganic compounds and eventually microbial contamination, while NSW contains, among other components, organic compounds, small amounts of nitrites and nitrates, trace elements and eventually EPS, from the bacterial activity. The levels of oxygen produce differences in the aggressivity of the samples, but the experiments were performed under anaerobic conditions; thus, the influence of the levels of oxygen does not have to be considered. A Meterlab portable $\mathrm{pH}$ meter (model pHM201) was used to measure the $\mathrm{pH}$. SEM studies were performed using a scanning electron microscope (JEOL, model JSM-6400). The EDS spectra were recorded with an $\mathrm{X}$-ray diffractometer (model Inca $\mathrm{x}$-sight, Oxford Instruments). The corrosion products were removed by dipping

Table 1 Chemical composition of the both solutions of seawater

\begin{tabular}{|c|c|c|c|c|c|c|c|c|c|c|}
\hline Ions & $\mathrm{Cl}^{-}$ & $\mathrm{HCO}_{3}^{-}$ & $\mathrm{NO}_{3}^{-}$ & $\mathrm{NO}_{2}^{-}$ & $\mathrm{F}^{-}$ & $\mathrm{Br}^{-}$ & $\mathrm{SO}_{4}^{2-}$ & $\mathrm{Na}^{+}$ & $\mathrm{K}^{+}$ & $\mathrm{Mg}^{2+}$ \\
\hline \multicolumn{11}{|c|}{ Concentration $\left(\mathrm{g} \mathrm{dm}^{-3}\right)$} \\
\hline $\mathrm{NSW}^{\mathrm{a}}$ & 20.0 & 0.2 & $<2 \times 10^{-3}$ & $<5 \times 10^{-6}$ & - & - & 2.9 & 11.0 & 0.4 & 1.3 \\
\hline ASW & 19.5 & 0.1 & - & - & 0.001 & 0.07 & 2.3 & 11.4 & 0.8 & 1.3 \\
\hline
\end{tabular}

${ }^{a}$ Other components certainly present in NSW (hydrocarbons, dissolved organic mater, microbes and a variety of colloidal substances) 
Table 2 Chemical physical properties of the ASW and NSW solutions

\begin{tabular}{lllll}
\hline Medium & Colour & Smell & $\mathrm{pH}_{20}{ }^{\circ} \mathrm{C}$ & $\chi_{20}{ }^{\circ} \mathrm{C}\left(\mathrm{mS} \mathrm{cm}^{-1}\right)$ \\
\hline ASW & Clear colourless & Odourless & 8.9 & 42.0 \\
NSW & Clear colourless & Odourless & 8.1 & 44.6 \\
\hline
\end{tabular}

the coupons for 5-10 s in a solution of sulphuric acid and potassium dichromate, according to standards ISO/DIS 8407 [13].

X-ray powder diffractograms were obtained with a Philips PW 1710 diffractometer equipped with a graphite monochromator coupled to a vertical goniometer (PW $1820)$. The $\mathrm{X}$-ray source $(\mathrm{Cu}-\mathrm{K} \alpha$ radiation) was operated at $30 \mathrm{~mA}$ and $40 \mathrm{kV}$, with automatic data acquisition (APD Philips (v 3.6 B) software). Diffractograms were obtained in the $2 \theta$ ranges of $3-90^{\circ}$ at a scan rate of $0.02^{\circ} \mathrm{s}^{-1}$.

\section{Results and discussion}

\subsection{Weight gains and losses}

The weight gains and corrosion rates of the brass samples corresponding to all the exposure periods are given in Table 3. Under anaerobic conditions in non-buffered solution exposures of 1 week lead to weight gains and corrosion rates slightly higher in ASW, but the 1 month exposure shows much higher weight gains in NSW (80 against $50 \mathrm{mg} \mathrm{dm}^{-2}$ ). This may be interpreted as a consequence of the microbial activity which in non-buffered medium may also contribute to lower the $\mathrm{pH}$. Actually, changes from 8 to 5.4 have been measured in non-buffered medium. Studying the corrosion of steel in a solution $1 \%$ of EPS from SRB, under anaerobic condition, Chan et al. [14] noticed significant changes in $\mathrm{pH}$ from 6 to 3.5 , probably related with the uronic acids constituents of the EPS. They observed an increase in the corrosion rate, up to 5-fold, attributable to compositional changes induced by the EPS.

Data in Table 3 also show that buffering (pH 9) leads to a big increase in the weight gains, particularly, for the
3 month exposures and, also to slight increases in the average corrosion rates. Samples with 1-month exposure in non-buffered ASW and NSW solutions present average corrosion rates of 3.7 and $5.3 \mathrm{mg} \mathrm{dm}^{-2}$ day $^{-1}$, while the corresponding values in buffered media are 4.1 and $6.2 \mathrm{mg} \mathrm{dm}^{-2} \mathrm{day}^{-1}$, respectively. The differences in terms of average corrosion rates would probably be more apparent if shorter exposure periods had been considered. In principle, the effect of buffering is quite surprisingly, since we would expect less corrosion in the buffered solutions (the system would react to local changes of the $\mathrm{pH})$. However, $\mathrm{pH} 9$ is a particular value affecting the solubility of zinc oxide/hydroxide compounds [15]. In order to confirm this hypothesis other buffering solutions, particularly those of near neutral $\mathrm{pH}$, will be tested.

Comparing the corrosion rates of brass in deoxygenated non-buffered ASW and NSW with data published in nondeoxygenated media $[9,10]$, it can be concluded that deoxygenation leads to significant increases in corrosion and also in the amounts of precipitates, at least for the 1 and 3 month exposures. However, we recognize that it would be important to also compare data corresponding to short time exposures.

\subsection{Visual observations}

The visual observation and optical images of the brass samples surfaces as well as the appearance of the solutions in which the brass coupons were immersed are summarized in Table 4.

The main differences concerning the colour of the corrosion products are observed on the 3-month exposed samples. While those from ASW have a yellow-greenish colour, those from immersion in NSW have a yellow-goldish colour. Precipitates in solution do not show differences in colour, but much higher amounts were formed in NSW.

According to the literature [15-17], the corrosion products of blue colour may be copper hydroxide, and copper chlorides, i.e. posnjakite, while the green colour is related to copper sulphates i.e. atacamite, paratacamite,

Table 3 Weight gains and corrosion rates of brass samples in non-buffered and buffered ASW and NSW, under anaerobic conditions

\begin{tabular}{|c|c|c|c|c|c|c|c|c|}
\hline \multirow{3}{*}{ Exposure time (day) } & \multicolumn{4}{|c|}{$+\Delta \mathrm{m}\left(\mathrm{mg} \mathrm{dm}^{-2}\right)$} & \multicolumn{4}{|c|}{$\mathrm{V}_{\text {corr }}\left(\mathrm{mg} \mathrm{dm}^{-2}\right.$ day $\left.^{-1}\right)$} \\
\hline & \multicolumn{2}{|l|}{ ASW } & \multicolumn{2}{|l|}{ NSW } & \multicolumn{2}{|l|}{ ASW } & \multicolumn{2}{|l|}{ NSW } \\
\hline & Non-buffered & $\mathrm{pH} 9$ & Non-buffered & $\mathrm{pH} 9$ & Non-buffered & pH 9 & Non-buffered & pH 9 \\
\hline 7 & 28 & - & 18 & - & 16 & - & 13 & - \\
\hline 30 & 50 & 60 & 80 & 132 & 3.7 & 4.1 & 5.3 & 6.2 \\
\hline 90 & 60 & 864 & 118 & 873 & 2.1 & 2.8 & 2.9 & 2.7 \\
\hline
\end{tabular}


Table 4 Visual observations on brass samples and solutions corresponding to the various exposure periods in ASW and NSW solutions

\begin{tabular}{|c|c|c|}
\hline System & Brass samples & Solutions appearance \\
\hline 1W/ASW & $\begin{array}{l}\text { Pink, reddish, blue-greenish and yellow } \\
\text { coloured zones }\end{array}$ & $\begin{array}{l}\text { Clear solution with white particles in } \\
\text { suspension }\end{array}$ \\
\hline 1W/NSW & $\begin{array}{l}\text { Pink, reddish, blue-greenish and yellow } \\
\text { coloured zones }\end{array}$ & $\begin{array}{l}\text { Clear solution with white particles in } \\
\text { suspension }\end{array}$ \\
\hline 1M/ASW & $\begin{array}{l}\text { Blue-greenish coloured zones, filiform } \\
\text { structures and colourless crystals }\end{array}$ & Clear solution and white precipitates \\
\hline $1 \mathrm{M} / \mathrm{NSW}$ & $\begin{array}{l}\text { Yellow greenish coloured compact film } \\
\text { and colourless crystals }\end{array}$ & $\begin{array}{l}\text { Cloudy solution with white and blue } \\
\text { precipitates }\end{array}$ \\
\hline 3M/ASW & Yellow-greenish coloured film & $\begin{array}{l}\text { Cloudy solution with big amount of white } \\
\text { and blue precipitates }\end{array}$ \\
\hline 3M/NSW & Yellow-goldish coloured film & $\begin{array}{l}\text { Cloudy solution with big amount of white } \\
\text { and blue precipitates }\end{array}$ \\
\hline
\end{tabular}

the formation of copper chloride complexes $\mathrm{CuCl}_{2}^{-}$and, subsequently, to copper chloride, $\mathrm{CuCl}$.

Species in solution may be $\mathrm{ZnOH}^{+}$or $\mathrm{HZnO}_{2}^{-}$ions, but the hydrozincite, $\mathrm{Zn}_{2}\left(\mathrm{CO}_{3}\right)_{2}(\mathrm{OH})_{6}$, a white compound, may precipitate. On the other hand, the observed blue colour of the solutions where the brass samples are immersed are certainly related to copper complexes or copper precipitates, i.e. $\mathrm{CuCl}_{2}^{-}, \mathrm{CuSO}_{4} \cdot 5 \mathrm{H}_{2} \mathrm{O}, \mathrm{CuCl}_{2} \cdot 2$ $\mathrm{H}_{2} \mathrm{O}$, among others. These compounds have been identified by Christy et al. [19] as precipitates of copper in solutions containing a mixture of $\mathrm{Cl}^{-}$and $\mathrm{SO}_{4}^{2-}$ ions.

\subsection{SEM/EDS studies}

Figure 1 gives the SEM images (BE) of brass samples immersed for 1 and 3 month in ASW and NSW solutions.
Fig. 1 SEM micrographs of brass samples from exposures of: (a) 1-month/ASW; (b) 1month/NSW; (c) 3-months/ ASW; (d) 3-months/NSW
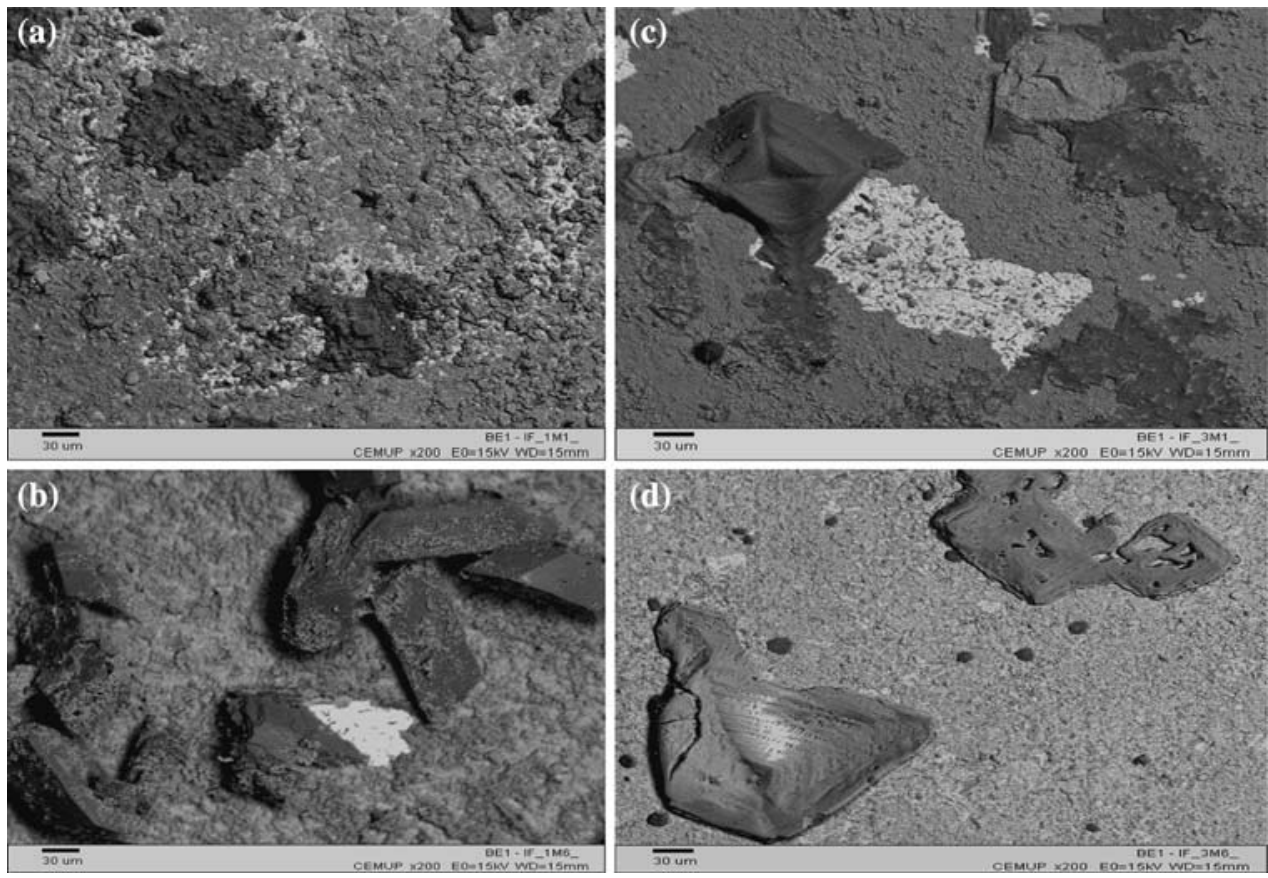
The surface morphology of samples with longer immersion times shows, as expected, a more severe attack. Those from 3-month immersion in NSW show intergranular pitting corrosion, while the corresponding samples from immersion in ASW show big crystals distributed all over the corrosion surface layer.

Figure 2a-d gives the compositional image (BE) and the X-ray emission spectra (EDS) of brass samples of 3-month immersions in non-buffered deoxygenated ASW. The SEM compositional contrast images (BE) and X-ray emission spectra (EDS) of brass samples from 3-month exposures in ASW show a white zone (Z1) of the base material, where most of the surface layer was removed; few crystals of sodium chloride (Z2) and a surface layer (Z3) with a complex composition including $\mathrm{Cl}, \mathrm{S}, \mathrm{O}, \mathrm{Ca}, \mathrm{Mg}, \mathrm{K}, \mathrm{Cu}$ and $\mathrm{Zn}$ (most probably chlorides, sulphates and oxides/ hydroxides).

On the other hand, the SEM compositional contrast images (BE) and the X-ray emission spectra (EDS) of brass samples immersed in NSW (Fig. 3) give the corresponding data of exposures in NSW. The images show a surface covered by a layer (Z1) with a complex composition including $\mathrm{Cl}, \mathrm{Mg}, \mathrm{O}, \mathrm{Cu}$ and $\mathrm{Zn}$ and, in smaller amounts, $\mathrm{S}$, $\mathrm{K}$ and Ca. A few large crystals (Z2) of sodium chloride and plenty of small localized deposits (Z3) with a high content of $\mathrm{S}, \mathrm{Ca}$ and $\mathrm{O}$ (possibly calcium sulphate) are also presented. It should be noted that those precipitates are almost uniformly distributed over the whole surface.

Figure 4 gives the contrast images (BE) of brass samples of 3 month exposure in ASW and NSW, after removal of the corrosion product. The surfaces of the two samples have distinct patterns: a cracked surface exhibiting intergranular pitting corrosion and spongeous areas, probably related to dezincification, on the samples from ASW immersions. Several black spots, probably traces of corrosion products distributed over the entire surface, on the samples from immersions in NSW, are apparent. It may be concluded that the black spots are due to remaining corrosion products, since the EDS has identified $\mathrm{S}$ as the main element, apart from $\mathrm{Cu}$ and $\mathrm{Zn}$, in such zones. Underneath the corrosion products, pits can be better visualized after complete removal of the remaining corrosion products.

\subsection{X-rays studies: corrosion products}

Figure 5a presents the X-ray diffractograms of the corrosion products formed on brass coupons immersed in deoxygenated non-buffered solutions of artificial and natural seawater, for 1 and 3 months. XDR patterns, corresponding to the corrosion products on the brass samples immersed for 3 months in a buffered ASW solution, are shown in Fig. 5 b.

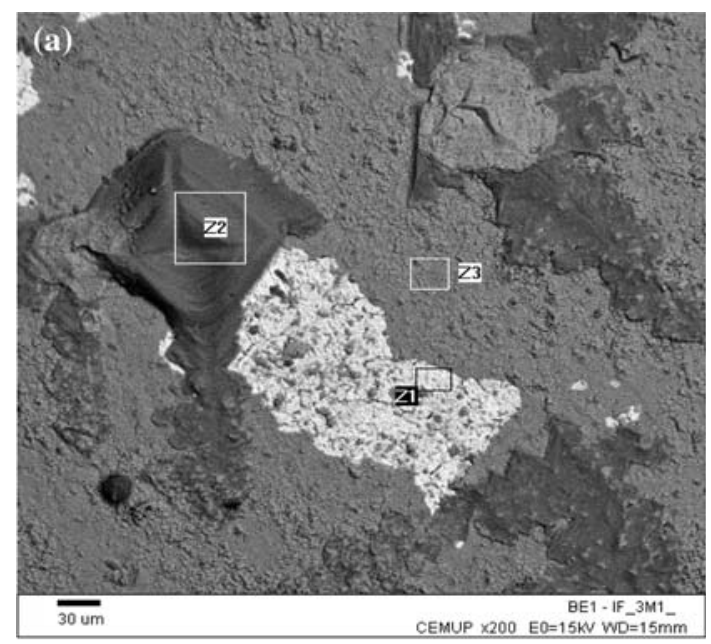

(b)

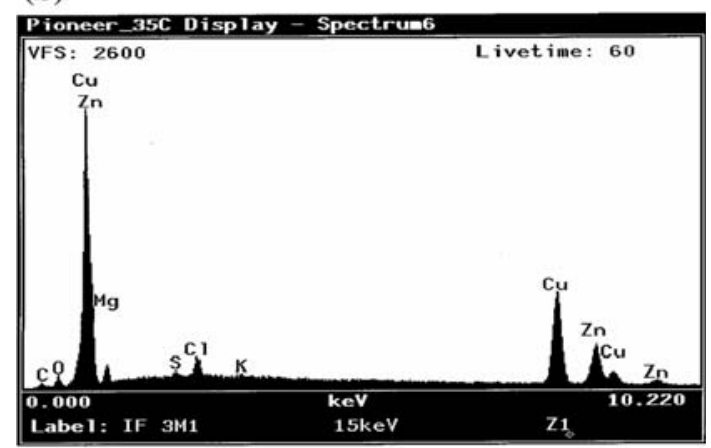

(c)

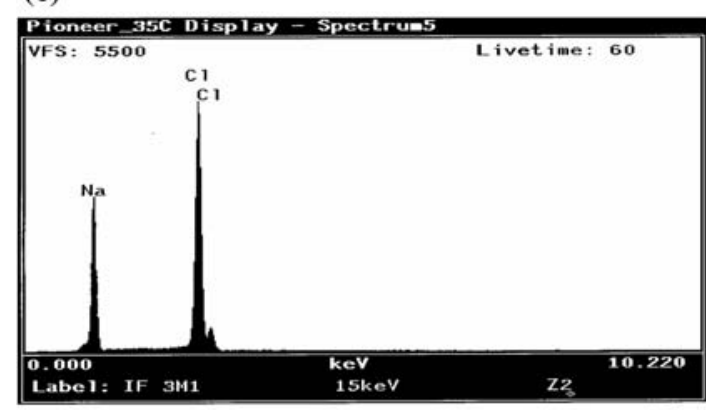

(d)

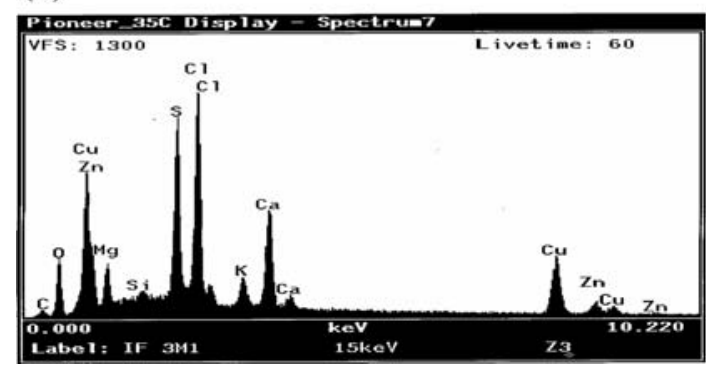

Fig. 2 SEM micrographs and EDS spectra of brass samples of 3-months exposures in non-buffered deoxygenated ASW

All the crystalline products identified on the brass samples by X-ray powder diffraction technique are given in Table 5. 


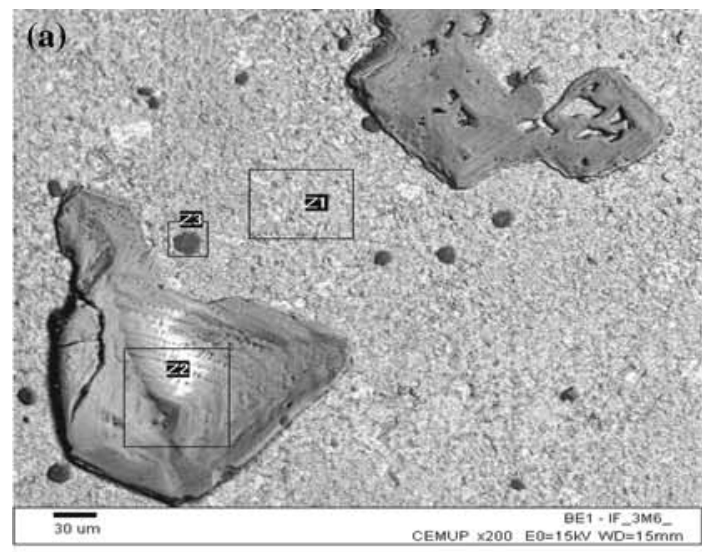

(b)

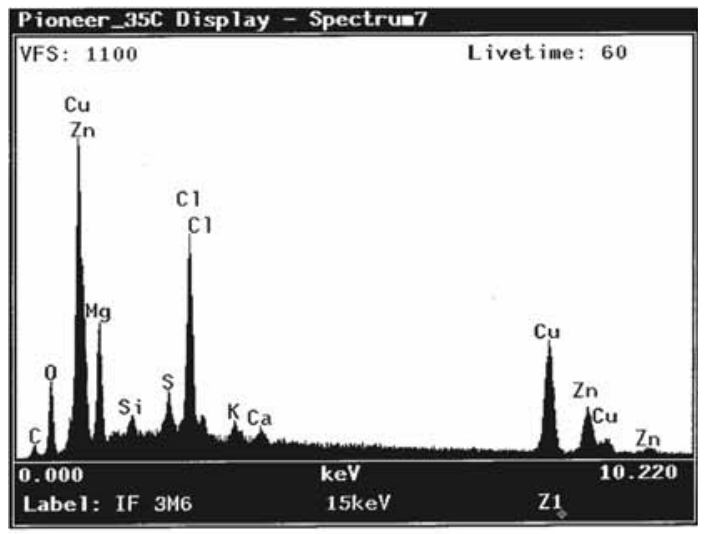

(c)

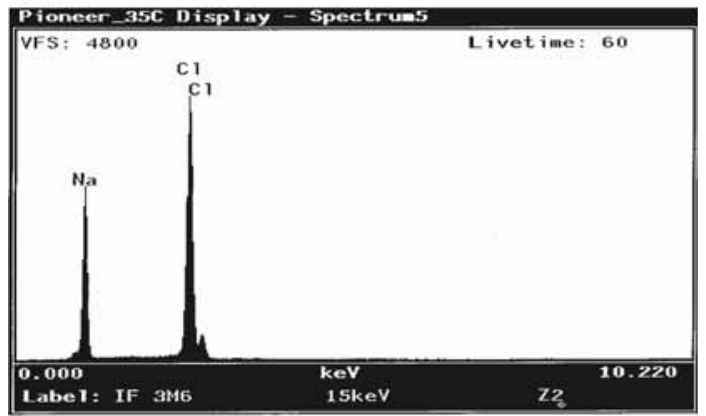

(d)

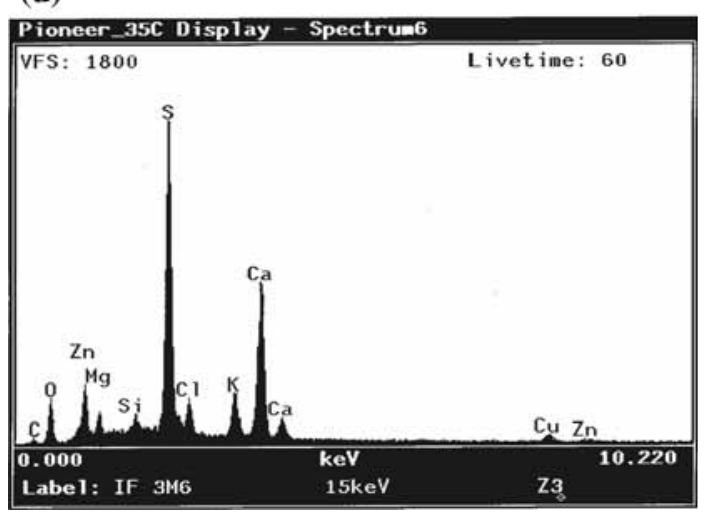

Fig. 3 SEM micrographs and EDS spectra of brass samples of 3-month exposures in non-buffered deoxygenated NSW
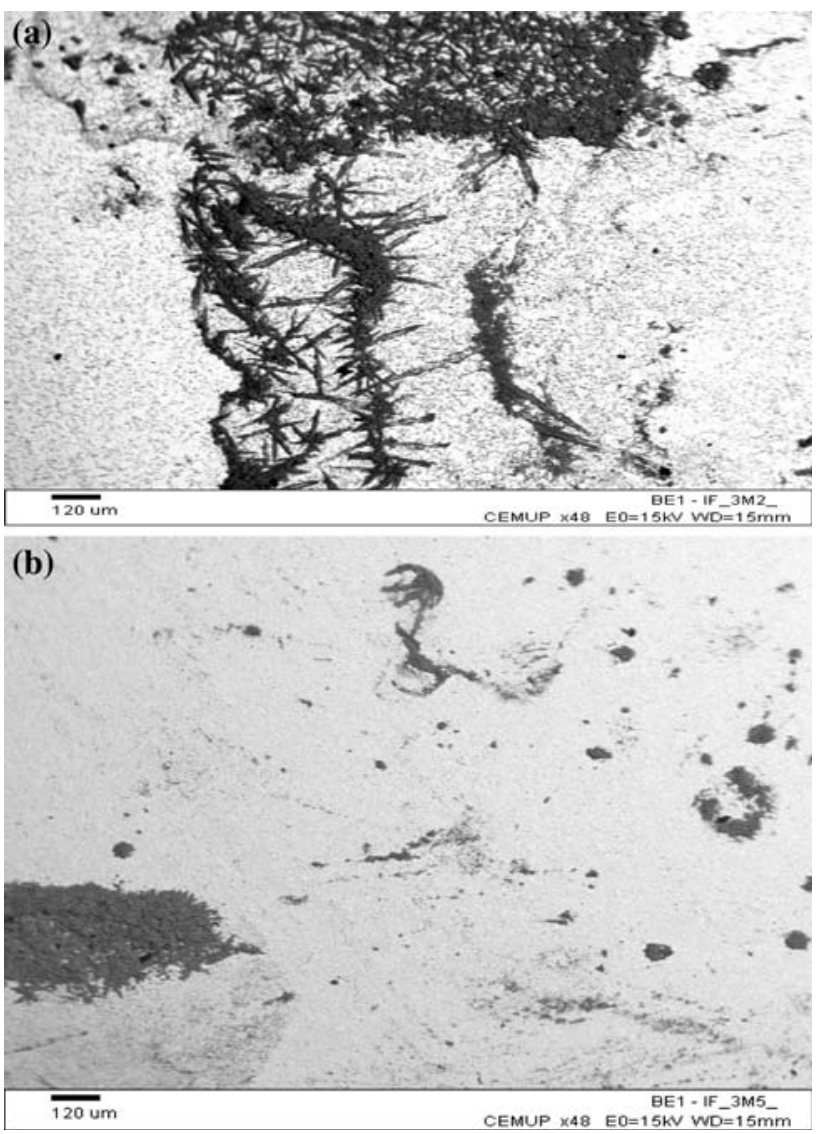

Fig. 4 SEM micrographs of brass samples of 3-month exposure in non-buffered deoxygenated seawater solutions, after the removal of the corrosion products: (a) ASW; (b) NSW

X-ray data show that, under anaerobic conditions, in non-buffered seawater solution, exposure of 1-month in ASW lead to the formation of posnjakite, only, while those in the NSW lead to the formation of atacamite, posnjakite, zinc hydroxi-chloride and hydrated zinc chloro-sulphate. However, on the 3-month exposed samples the crystalline corrosion products were the same on both samples (atacamite, posnjakite and hydrated zinc chloro-sulphate). Buffering the ASW leads to the same corrosion products as those obtained in non-buffered ASW. It should be noted that according to the $\mathrm{X}$-ray data, the zinc hydroxi-chloride, $\mathrm{Zn}_{5}(\mathrm{OH})_{8} \mathrm{Cl}_{2}$, is not seen on the 3 month exposed samples; most probably this compound has been transformed or dissolved at longer exposure times.

The large precipitates observed on the SEM images of all samples were identified as $\mathrm{NaCl}$, but they may be just precipitates from the electrolyte and hence their presence at the surface may only be a question of cleaning, with no relation to corrosion behaviour.

According to the literature [16-19] the formation of atacamite may result from the interaction of $\mathrm{Cu}^{2+}$ ions or $\mathrm{Cu}$ (I) oxide with chlorides in solution, i.e. 
Fig. 5 X-ray powder diffractograms of the crystalline corrosion products formed on brass coupons immersed during: (a) 1 and 3 month in nonbuffered ASW and NSW solutions; (b) 3-month in buffered (pH 9) and nonbuffered ASW
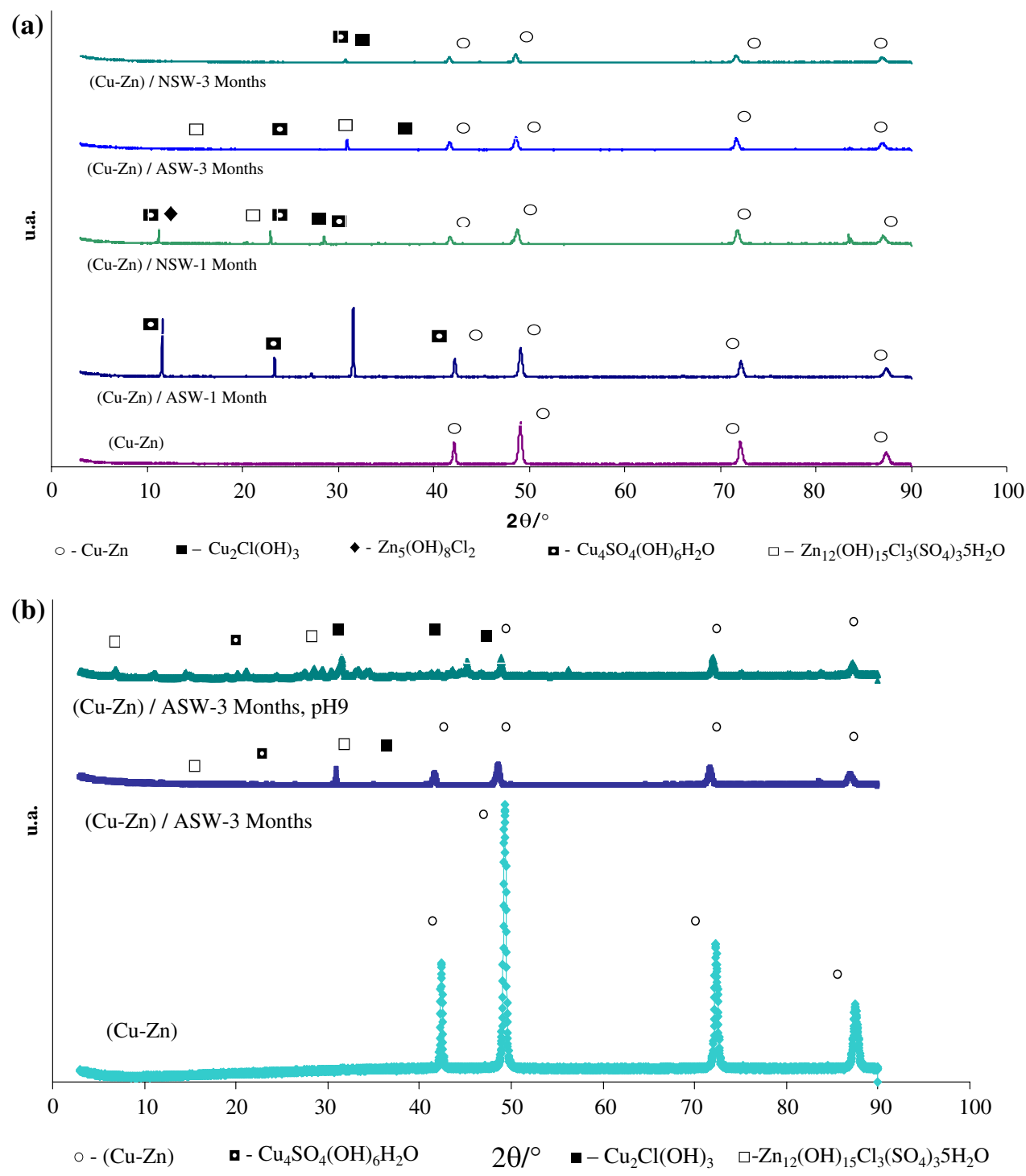

Table 5 Crystalline corrosion compounds on the 1 and 3 months exposed brass samples

\begin{tabular}{|c|c|c|c|c|c|c|}
\hline \multirow[t]{2}{*}{ Compounds } & \multirow[t]{2}{*}{ Colour } & \multicolumn{4}{|c|}{ Non-buffered } & \multirow{2}{*}{$\begin{array}{l}\text { Buffered pH } 9 \\
\text { 3M/ASW }\end{array}$} \\
\hline & & $\begin{array}{l}1 \mathrm{M} / \\
\mathrm{NSW}\end{array}$ & $\begin{array}{l}1 \mathrm{M} / \\
\text { ASW }\end{array}$ & $\begin{array}{l}3 \mathrm{M} / \\
\mathrm{NSW}\end{array}$ & $\begin{array}{l}3 \mathrm{M} / \\
\text { ASW }\end{array}$ & \\
\hline Atacamite, $\mathrm{Cu}_{2} \mathrm{Cl}(\mathrm{OH})_{3}$ & Dark green & $\sqrt{ }$ & - & $\sqrt{ }$ & $\sqrt{ }$ & $\sqrt{ }$ \\
\hline Posnjakite, $\mathrm{Cu}_{4} \mathrm{SO}_{4}(\mathrm{OH})_{6} \cdot \mathrm{H}_{2} \mathrm{O}$ & Sky blue to dark blue & $\sqrt{ }$ & $\sqrt{ }$ & $\sqrt{ }$ & $\sqrt{ }$ & $\sqrt{ }$ \\
\hline Zinc hydroxi-chloride, $\mathrm{Zn}_{5}(\mathrm{OH})_{8} \mathrm{Cl}_{2}$ & Pink & $\sqrt{ }$ & - & - & - & - \\
\hline Hydrated zinc cloro-sulphate, $\mathrm{Zn}_{12}(\mathrm{OH})_{15} \mathrm{Cl}_{3}\left(\mathrm{SO}_{4}\right)_{3} \cdot 5 \mathrm{H}_{2} \mathrm{O}$ & White & $\sqrt{ }$ & $\sqrt{ }$ & $\sqrt{ }$ & $\sqrt{ }$ & $\sqrt{ }$ \\
\hline
\end{tabular}

$2 \mathrm{Cu}^{2+}+\mathrm{Cl}^{-}+3 \mathrm{H}_{2} \mathrm{O} \rightarrow \mathrm{Cu}_{2} \mathrm{Cl}(\mathrm{OH})_{3}+3 \mathrm{H}^{+}$
$\mathrm{Cu}_{2} \mathrm{O}+\mathrm{Cl}^{-}+\frac{1}{2} \mathrm{O}_{2}+2 \mathrm{H}_{2} \mathrm{O} \rightarrow \mathrm{Cu}_{2} \mathrm{Cl}(\mathrm{OH})_{3}+\mathrm{OH}^{-}$

Posnjakite may result from the oxidation of $\mathrm{Cu}(\mathrm{I})$ to $\mathrm{Cu}$ (II) species, which, in the presence of $\mathrm{SO}_{4}^{2-}$ ions, leads to:

$$
\begin{gathered}
2 \mathrm{Cu}_{2} \mathrm{O}+\mathrm{SO}_{4}^{2-}+4 \mathrm{H}_{2} \mathrm{O}+\frac{1}{2} \mathrm{O}_{2} \rightarrow \mathrm{Cu}_{4}\left(\mathrm{SO}_{4}\right)(\mathrm{OH})_{6} \\
\cdot \mathrm{H}_{2} \mathrm{O}
\end{gathered}
$$

On the other hand, the zinc hydroxi-chloride was mentioned in the literature by Maxted [20] and also by Qu et al. 
[21]. This compound may result from the interaction of $\mathrm{ZnO}$ with chloride ions, i.e.

$4 \mathrm{ZnO}+\mathrm{Zn}^{2+}+2 \mathrm{Cl}^{-}+4 \mathrm{H}_{2} \mathrm{O} \rightarrow \mathrm{Zn}_{5}(\mathrm{OH})_{8} \mathrm{Cl}_{2}$

In its turn, the hydrated zinc chloro-sulphate may result from the following reaction [22, 23]:

$$
\begin{aligned}
& 9 \mathrm{Zn}^{2+}+15 \mathrm{ZnO}+6 \mathrm{SO}_{4}^{2-}+25 \mathrm{H}_{2} \mathrm{O}+6 \mathrm{Cl}^{-} \\
& \quad \rightarrow 2 \mathrm{Zn}_{12}(\mathrm{OH})_{15} \mathrm{Cl}_{3}\left(\mathrm{SO}_{4}\right)_{3} \cdot 5 \mathrm{H}_{2} \mathrm{O} .
\end{aligned}
$$

The hydrated zinc chloro-sulphate compound apparently occurs in media with high concentrations of $\mathrm{Cl}^{-}$and $\mathrm{SO}_{4}^{2-}$.

It should be mentioned that $\mathrm{Cu}(\mathrm{II})$ oxide/hydroxide, which has often been reported to form as an outlayer above the inner $\mathrm{Cu}$ (I) oxide, was not detected. A similar behaviour has been reported by Christy et al. [19] on a study of copper in simulated potable water. Most probably the $\mathrm{Cl}^{-}$and $\mathrm{SO}_{4}^{2-}$ ions react rapidly with $\mathrm{Cu}$ (II) species leading to water soluble species, such as $\mathrm{CuCl}_{2}$ and $\mathrm{CuSO}_{4}$ which may then lead to the precipitates $\mathrm{CuCl}_{2} \cdot 2 \mathrm{H}_{2} \mathrm{O}$ and $\mathrm{CuSO}_{4} \cdot 5 \mathrm{H}_{2} \mathrm{O}$. According to our X-ray data, the passive layer on brass in seawater solutions may comprise copper and zinc containing minerals (cuprite, atacamite, ponsjakite and zinc hydroxi chloride), which may be responsible for the passivity of brass observed only during short exposures, i.e. less than 1 month. Between the 1 and the 3 month exposures, the weight losses were quite high which means that passivity breaks down, at least on some areas. The occurrence of atacamite, posnjakite and hydrated zinc chloro-sulphate together suggests a complex relationship between $\mathrm{Cl}^{-}$and $\mathrm{SO}_{4}^{2-}$ ions on the corrosion of brass in seawater.

\section{Conclusions}

Under anaerobic conditions, higher corrosion rates and higher amounts of corrosion products were observed on brass samples immersed in NSW, this being probably due to the presence of organic matter and/or to the microorganism activity in deoxygenated NSW.

Buffering at $\mathrm{pH}$ 9, under anaerobic conditions, causes large increases in the weight gains in both media and to slight increases in the corrosion rates on long exposures. However, short term exposures have not been analyzed.

The corrosion of brass leads also to the formation of precipitates in both media. In non-buffered media the amounts were higher in NSW, but in buffered media, $\mathrm{pH} 9$, the amounts of precipitates were quite high in both media. The buffering effect seems to dominate.

The SEM data confirm the influence of the medium on the morphology of the corrosion layer, as well as on both the size and morphology of the pits underneath the corrosion products.
XPS data show that the medium does not significantly affect the nature of the crystalline corrosion products, on the 1 and 3 month exposed samples, which were mainly atacamite, $\mathrm{Cu}_{2} \mathrm{Cl}(\mathrm{OH})_{3}$, posnjakite, $\mathrm{Cu}_{4} \mathrm{SO}_{4}(\mathrm{OH})_{6} \cdot \mathrm{H}_{2} \mathrm{O}$ and hydrated zinc basic chloride-sulphate, $\mathrm{Zn}_{12}(\mathrm{OH})_{15}$ $\mathrm{Cl}_{3}\left(\mathrm{SO}_{4}\right)_{3} \cdot 5 \mathrm{H}_{2} \mathrm{O}$. The zinc hydroxide-chloride, $\mathrm{Zn}_{5}(\mathrm{OH})_{8} \mathrm{Cl}_{2}$, was observed only on the 1 month exposures in NSW. Most probably, if the 1 week exposed samples had been analyzed, then the pink compound, zinc hydroxide-chloride, would have been identified. The formation of the hydrated zinc basic chloride-sulphates, $\mathrm{Zn}_{12}(\mathrm{OH})_{15} \mathrm{Cl}_{3}\left(\mathrm{SO}_{4}\right)_{3} \cdot 5 \mathrm{H}_{2} \mathrm{O}$, occurs in all the samples.

Cuprite was certainly present on the 1 week exposed samples, since a reddish colour was observed. However, those samples were not analyzed by XRD.

In general it can be concluded that the removal of dissolved $\mathrm{O}_{2}$ and buffering at $\mathrm{pH} 9$ contribute to enhanced corrosion of brass in seawater.

Acknowledgments The authors acknowledge the Portuguese Foundation for Science and Technology (FCT) for financial support and Doctor C. Sá, from the Centro de Materiais da Universidade do Porto (CEMUP), for all the help and assistance in the SEM/EDS studies. FCT is also acknowledged for financial support to Centro de Ciências Moleculares e Materiais (CCMM) and Unidade de Química Ambiental [528].

\section{References}

1. Blunn G (1986) Biological fouling of copper and copper alloys in biodeterioration. In: Barry S, Houghton DR, Llewellyn GC and O'Rear CE (eds). CAB International Mycological Institute and The Biodeterioration Society, London

2. Wang YZ, Beccaria AM, Poggi G (1994) Corros Sci 36:1273

3. Mansfeld F, Little B (1992) Electrochim Acta 37:2291

4. Liu J, Zhen J, Xu L (2001) Mater Corros 52:833

5. Huang G, Chan K-Yu, Fang HHP (2004) J Electrochem Soc 151:B434

6. Rodrigues LFTG, Antunes RMM, Neto RPC and Sequeira CAC (1998) In: Euromat'98, Portuguese Materials Society, Lisbon, Portugal

7. Kharafi FCM, Atheya BG, Adb-Allah RM (2004) J Appl Electrochem 47:53

8. Hostis VL, Dagbergt C, Féron D (2003) Electrochim Acta 48:1451

9. Santos CS, Mendonça MH, Fonseca ITE (2006) J Appl Electrochem $36: 1353$

10. Santos CS (2005) Master thesis, University of Lisboa, Lisboa, Portugal

11. Nagiub A, Mansfeld F (2002) Electrochim Acta 47:2319

12. Standards Methods for Examination of Water and Wastewater (1975) In: Rand MC, Arnold WFC, Greenberg EG, Taras MJ (eds), 4th edn. American Public Health Association, Washington $\mathrm{DC}$

13. ISO/DIS 8407 (1986) Metal and alloys procedure for the removal of the corrosion products from corrosion tests specimens. Geneve, Switzerland

14. Shan K-Y, Xu L-C, Fang HHP (2002) Environ Sci Technol $36: 1720$ 
15. Pourbaix M (1966) Atlas of electrochemical equilibria. Cebelcorr, Pergamon Press, Brussels

16. [ACRYM] (1992) The on line American mineralogist crystal structure data base. London

17. Perroud P, (2005) Athena mineralogy (http://un2sg4.unige.ch/ athena/mineral/mineral.html)

18. Fitzgerald KP, Nairn J, Atrens A (1998) Corros Sci 40:2029

19. Christy AG, Otieno-Alego V, Stoll M, Webster RD (2004) J Appl Electrochem 34:225
20. Maxted J (1999) Paper 15 in JCSE, Vol. 2. In: Cottis B (ed). Cambridge

21. Qu Q, Yan C, Yan Y, Cao C (2002) Corros Sci 44:2789

22. Strandberg H, Johansson L-G (1998) J Electrochem Soc 145:2029

23. Lyon SB, Thompson GE, Johnson JB, Wood GC, Ferguson JM (1987) Corros NACE 43:719 